\title{
Perverse incentives and the political economy of South African academic journal publishing
}

AUTHOR:

Keyan G. Tomaselli'

\section{AFFILIATION:}

${ }^{1}$ Department of Communication Studies, University of Johannesburg, Johannesburg, South Africa

\section{CORRESPONDENCE TO: \\ Keyan Tomaselli}

EMAIL:

Keyant@uj.ac.za

\section{DATES:}

Received: 29 Jan. 2018

Revised: 02 Feb. 2018

Accepted: 24 July 2018

Published: 27 Nov. 2018

\section{KEYWORDS:}

rent-seeking; publication subsidy; cultural economy;

South Africa; research incentives

\section{HOW TO CITE:}

Tomaselli KG. Perverse

incentives and the political economy of South African academic journal publishing. S Afr J Sci. 2018;114(11/12), Art. \#4341, 6 pages. https://doi. org/10.17159/sajs.2018/4341

\section{ARTICLE INCLUDES: \\ $\times$ Supplementary material \\ $\times$ Data set}

FUNDING:

None (c) 2018. The Author(s). Published under a Creative Commons Attribution Licence.
Academic publishing in South Africa attracts a state research incentive for the universities to which the authors are affiliated. The aim of this study was twofold: (1) to examine the composition of the research value chain and (2) to identify the effects of broken links within the chain. The methodology selected was a lived cultural economy study, which was constructed through incorporating dialogue with editors, authors and researchers in terms of my own experience as a journal editor, read through a political economy framework. The prime effect is to exclude journals, especially independent titles, from directly earning publishing incentives. The behaviour of universities in attracting this variable income is discussed in terms of rent-seeking which occurs when organisations and/or individuals leverage resources from state institutions. Firstly, this process commodifies research and its product, publication. Secondly, the value chain is incomplete as it is the journals that are funding publication rather than - in many cases - the research economy funding the journals. Thirdly, authors are seeking the rewards enabled by the incentive attached to measurement systems, rather than the incentive of impacting the discipline/s which they are addressing. Fourthly, the paper discuses some policy and institutional matters which impact the above and the relative costs between open access and subscription models. Editors, journals and publishers are the un- or underfunded conduits that enable the transfer of massive research subsidies to universities and authors, and, in the case of journals, editors' voluntary work is the concealed link in the value chain enabling the national research economy.

\section{Significance:}

- The South African scientific publishing economy is built on a foundation of clay: this economy distorts research impact and encourages universities and academics to commoditise output.

\section{Introduction}

Amongst the items usually under discussion in academia are peer review and the alleged unreasonable profits made by multinational publishing firms. ${ }^{1}$ Allied to these are issues of open access. ${ }^{2}$ Finally, the question of predatory journals that prey on the 'publish or perish' syndrome is a growing concern. ${ }^{3-6}$ These four topics background more specific concerns addressed here regarding the issue of incentive-seeking by South African universities, enabled by the unique economics of academic journal publishing in South Africa. This uniqueness is illustrated in the final section which draws on the textured experience of a number of editors and production editors based in South Africa who have commented, some multiple times, on earlier drafts of this analysis. My conclusion is that the business of academic journal publishing has, as a consequence of the way in which research is funded from the public purse, become the business of subsidising aspects of the business of education.

South African universities earn substantial rewards from the Department of Higher Education and Training (DHET) when their affiliates (academics, students and honorary appointments) publish in the journals that comprise 'the DHET-accredited list'. The benefit of this DHET incentive mechanism has been a significantly increased publication output and amplified productivity, through encouraging more academics to engage in research and publication. However, the negative outcome is that this system drives many universities to become rent-seeking, or at minimum, engage in the pursuit of perverse incentives. Rent-seeking is:

The process whereby organisations or individuals expend resources to obtain actions from state institutions that allow these actors to earn 'rents' in excess of what they would earn in the hypothetical scenario of a competitive market. ${ }^{7}$

Allied to my use of rent-seeking is the term 'perverse incentive', that is, an unintended and sometimes undesirable outcome that contravenes the intention of the incentive's designers, in this case the state's policymakers. Incentive payments for publication in journals is unique to South Africa.

The hard data identifying incentive-seeking behaviour with regard to (1) universities, (2) specific journals and (3) even specific authors, has been summated in omnibus quantitative surveys conducted by the Centre for Research on Evaluation, Science and Technology (CREST, Stellenbosch University) for the Academy of Science of South Africa (ASSAf). ${ }^{6}$ My analysis draws directly on this hard data.

Incentive-seeking behaviour involves effort by private interests to capture excess rent/surplus by influencing the state's use of its power. Social harm is thereby caused in two main ways, the first of which is through distortion in the allocation of resources, the details of which depend on what precisely the rent-seeking concerns. The second is through the costs incurred by those private (in our case, public universities) interests in seeking to secure this outcome. ${ }^{8,9}$ DHET's financial incentive scheme encourages publication through the way that resources are transferred to universities. This incentive occurs in the state's generation of a new form of 'surplus' - one 
that typifies the knowledge economy in which information becomes an intangible commercial good - that can be pursued by researchers. The rules for accessing that surplus are weak, as will become evident below. ${ }^{6,7}$ The use of extrinsic incentives, however, leads to rent-seeking behaviour at lower levels. The publication churn in predatory or lowquality journals is one response to the incentive. Another is the policy adopted by some institutions to allocate a portion of the incentive directly to individuals as taxable income. Anecdotal evidence further reveals corrupt agreements by some individuals who have deliberately published in known predatory, but nevertheless accredited titles, like the Mediterranean Journal of Social Sciences. ${ }^{4,7}$

The system's design exposes it to abuse and fails to address intellectual or academic quality in a satisfactory way, other than via ASSAf's 5-yearly journal assessments (see below). Kerr and de Jager ${ }^{5}$ and Mouton ${ }^{6}$ have shown that some journals on the DHET list (mainly listed on the ProQuest International Bibliography of Social Sciences) have been also classified as 'predatory' on Beall's List (http://beallslist.weebly.com).

Apart from the above-discussed unintended consequences flowing from the application of the DHET incentive system by individual universities, the scheme is structurally flawed because it resources only some links of the value chain. A value chain links the complete range of actions - in the case of journals, editorial, peer review, design, production, marketing and distribution - that combine to deliver a product or service. In academic research, the value chain starts with the raw material (research data) used by researchers to make their products (articles), and includes all add-ons prior to the published work being sold to markets (libraries, students, academics, researchers, policymakers, etc.) (Figure 1).

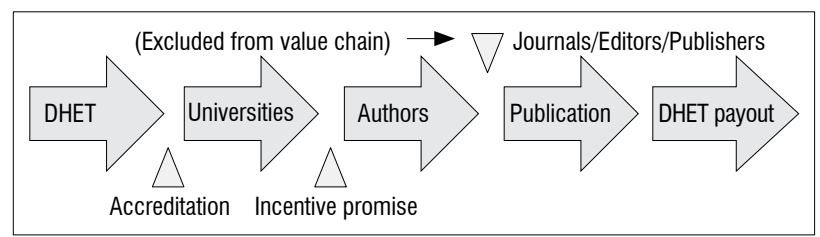

Figure 1: The journal publishing value chain.

The supply of articles and the purchase of journal subscriptions are resourced within the value chain. Unresourced within the chain, however, are editorial, peer review, production and publishing processes. Only two journal editors questioned the ideological motivation of the DHET system when it was first introduced in the early 1980s, but they both missed the financial basis of the initiative where non-state-funded journals were concerned - an omission that has continued into the current post-apartheid period. These were the editors of Critical Arts (Tomaselli et al. ${ }^{10}$ ) and Scrutiny2 (Diedre Byrne ${ }^{11}$ ). The system is now driven by neoliberal productivity imperatives rather than apartheid ideology. That is to say, the editors of these two journals had argued that the apartheid Department of Education's incentive system was designed to shape research outcomes in its favour by accrediting specific journals. The application process at that point was opaque and the selection criteria of journals was unknown, as was the entity or committee or office that actually conferred 'accreditation'.

As the financial support of peer-review, editorial and production costs continue to be excluded by the value chain, the system imposes burdens on editors and peer reviewers in terms of article oversupply. This oversupply is not only a natural consequence of increasing research productivity, but also a consequence of rent-seeking. These outcomes are related: the research economy is characterised by post-publication resources (the incentives) generating production capacity on the one hand and the oversupply of submissions (as a kind of pre-product) on the other hand. This asymmetry is analysed here through examining (1) the political economy of the national research publication system, specifically (2) the exploitation of voluntary editors and reviewers; and identifying (3) instances of perverse incentive-seeking by universities which leverage journals and authors (including graduate students) as 'cash cows'.

\section{Accredited journals}

South African university administrations are obsessed with their faculty publishing in so-called 'accredited journals'. From an unknown selection process during apartheid, an accredited journal now meets clear publicised and monitored technical and editorial criteria determined by DHET. Journals indexed on Clarivate Analytics' (previously Thomson Reuters') Web of Science, the ProQuest International Bibliography of Social Sciences (IBSS) and Scopus are accorded honorary accreditation. The inclusion of the Norwegian list is not mentioned here as this choice has never been satisfactorily explained by DHET at ASSAf's National Scholarly Editors' Forums. That is to say, these indexes are exempted from the DHET's technical evaluative process but the journals indexed are conferred 'accreditation' status.

Universities confer economic value to these lists, firstly because publishing in accredited titles earns variable subsidy from DHET for the authors' institutions in the form of a publication incentive of about ZAR120 000 (the amount varies annually, depending on the DHET annual budget). Secondly, the system provides proof to government of due productivity in the lists that it recognises (rather than also those additional lists that academics themselves recognise).

\section{Value chain contradictions}

A value chain describes a process view of organisations as a system, composed of subsystems, each with inputs, transformation processes and outputs. An efficiently operating value chain reduces cost, optimises efficiency, eliminates waste and enables competitive advantage (such as in university rankings). Academia, however, is the only industry that deliberately encourages overproduction, irrespective of markets, outlets or consumers (readers, libraries, or retailers). The research has been done, the writing completed, and the papers submitted. But the majority of submissions are rejected by the top international journals, and of those published, many products (articles) might not find a viable readership and are rarely cited. Overproduction leads to overburdened editors and reviewers; a waste of resources; fewer citations; and opportunity cost of reduced focus on educational activities. The result is less chance of the average academic producing a few valuable articles rather than many worthless articles over their career (De Jager P 2017, written communication, October 15). Social value is equated by universities to measurable economic value, that is, incentive subsidy, thereby increasing pressure on academics to 'perform' (publish, secure grants, advance fields of study and attract third-stream income). ${ }^{12}$

However, the very same articles would most likely find easier access to journals in the domestic DHET-list and to those open-access journals constituted specifically to service and absorb the oversupply of product/articles. ${ }^{2}$ The DHET reward for publication is the same across all accredited publications; the preparation, submission and revision costs - in terms of actual time and ability required - are lower and the probability of acceptance is higher for lower-quality journals. ${ }^{7}$ In South Africa, this production inflation is met by an oversupply of 'accredited' journals that have emerged to take up the slack. For example, 19 journals service the discipline of management studies in South Africa. An analysis of 371 articles appearing in journals in this field in 2011 revealed a cost to government of subsidising plagiarised work in these journals at ZAR7 million from a total payout to universities of ZAR32 $400000 . .^{13}$ (See also de Jager et al. ${ }^{3}$ ).

Overproduction explains the rise of megajournals such as PLOS ONE that promise quick acceptance and publication turnaround (Mouton J 2017, written communication, June 6). A knock-on effect is that some South African open-access journals owned by a private company are now engaging in 'market-related' pricing (with regard to the DHET incentive). The example below compares the cost of conventional and open-access publishing. According to the homepage of the open-access journal HTS Theological Studies, to use a specific example, the article-processing charge (APC) for publishing in 2017 was ZAR1073 per A4 output page in PDF, with the average article length reportedly 8 pages. Because this journal is indexed in Web of Science, the DHET rule introduced in 2015 pertaining to a maximum of $25 \%$ authorship from a single institution does 
not apply. That is, an online publication for a single issue can include over a hundred articles when previously 10 might have been feasible in terms of hard copy page allocation. The rule was introduced to discourage rent-seeking by journals that were in the habit of publishing the majority of papers authored by academics from the publication's home base. The previous 50:50 split was recast to 25:75 between 'home' and external authors publishing in any single issue. ${ }^{14}$

Using an issue of HTS as an example (issue 73(3) of 2017): nine Unisaaffiliated authors published in this issue, contributing APCs totalling ZAR77 256. In comparison, the typical subscription cost (print and electronic) of two Brill academic theology journals - Numen and Novum Testamentum - was EUR545 (ZAR8175) and EUR396 (ZAR5940), respectively. Both of these journals are indexed by Web of Science and Scopus, with all the associated benefits of high visibility, ranking and metrics... and with no APCs. Thus, if all nine Unisa-affiliated authors had published in one of these subscription journals, the same access to the same articles would have cost ZAR14 115, and the authors would have received the benefit of a bigger proportion of the subsidy because both these journals are indexed by Web of Science and Scopus. The question is, of course, whether any of the articles would have been published in Numen and Novum Testamentum for which selection standards might have been more competitive. The comparison suggests that the openaccess author-pays model as currently operating in South Africa might not actually be a cost saver. As van den Heever, who provided the above example, concludes:

$$
\begin{aligned}
& \text {...for the price of publishing } 9 \text { articles in one } \\
& \text { journal, the university could have obtained access } \\
& \text { to about } 12 \text { other journals, a consideration of which, } \\
& \text { in a context of austerity and cut-backs to library } \\
& \text { investments and subscriptions, is a factor [of] very } \\
& \text { great importance (van den Heever G 2017, written } \\
& \text { communication, September 4). }
\end{aligned}
$$

This kind of pricing nuance between open-access and subscription journals needs to be properly assessed when budgeting research awards and costs. Now overlaid on the budgeting consideration is that performance management regimes require minimum publication targets, in accredited titles, for staff. This 'virtual' dependency has created an institutional equilibrium in which an increasing proportion of South African based academics are wilful (or reluctant) participants in perverse incentive-seeking conduct. It then becomes impossible to separate institutional characteristics from individual behaviour. ${ }^{7}$

\section{Cash cows: Accreditation (the branding) and journals (the factory)}

Let us metaphorically compare the practice of accreditation that results in overproduction to the way that a dairy farmer operates with regard to retail markets. The metaphorical discourse of 'cash cows' dominates discussions within university committees. Third-stream publication income is not discussed within committees in terms of 'rent-seeking' behaviour or perverseness. Incentive-seeking discourse framed by the third-stream category predominates. In other words, university managers and committees talk about maximising income via manipulating the possibility of variable income that is enabled by leveraging the DHET publication incentive mechanism to the hilt, and additionally requiring their staff to raise their own funds from funders, donors, research bodies and so on. This is known as 'third-stream' income - the first being (declining) state subsidy and the second being (since 2017, declining) student fees.

In the analogy, let us assume that the dairy owns 100 cows that are milked twice daily for processed products that will be bought by 50 supermarkets which also purchase from other dairies. The supermarkets in the delivery area can only sell 1000 units a day bought from the dairies, so they do not purchase more than that. The dairies do not produce more than they can sell, unless of course they get government subsidies for quantity rather than for sales and consumption. The government subsidies result in overproduction and the mass destruction of unsold milk products. This also keeps the price at a viable level for both farmer and supermarket at the taxpayer's expense.

Likewise, the South African academy insists on overproduction and restricts submission to 'accredited' supermarkets (journals) which are, by default, conferred their qualifying brands by DHET. These 'brands' (lists) then enable the seeking that funds universities but rarely journals. The value chain thus ignores hidden costs, including that of peer review, editing and production. These are delivered 'free of charge' by academics and publishers, but utilise university time and infrastructure - underwritten by the taxpayer.

The cows (i.e. academics), however, get punished for the overproduction of articles placed in non-accredited titles - a glut that is caused by management (the dairy factory) in the first place. Punishment for publishing in journals outside the approved lists takes different forms at different universities. In the weak case, authors are not rewarded and/or their unaccredited publications are not listed in their university's annual report. In stronger cases, such authors are called in by deans for 'counselling', and in the strongest case they may forfeit notch increases, promotion and superannuation. On the other hand, the overproduction could be intellectually valorised by being published in other kinds of fora, including non-accredited peer-reviewed publications, informed and professional magazines, textbooks, subvented books, blogs, letters, commentaries, and so on. However, these outputs are institutionally discouraged because they do not earn DHET subsidy and the social value of such publications is depreciated in research and performance management committees. Yet it was never DHET's intention that publication in the wider unaccredited circuits be discouraged. This consequence has been one of the negative externalities of the way that most South African universities have distorted the policy.

Most universities reward the individual cows (authors) rather than the supermarkets (journals) that take the risk, do the editorial work and publish their output. Many universities top slice a portion of the DHET research incentive of ZAR120 000 for the author's university research code, which can be used for various expenses such as conference fees, employment of student researchers, page fees, book purchasing and article processing charges. Some universities even permit the authors employed by them to appropriate a portion of the incentive as taxable income, thus encouraging active rent-seeking by individual authors, which could be as high as ZAR80 000 an article. The cows thus behave as rent-seekers and keep producing more and more milk (articles) than can be stocked and sold by the approved (mostly non-subsidised) supermarkets (journals).

The expectation of the factories (the universities), as articulated by submitting authors, is that the supermarkets (journals) must 'buy' the milk (articles) no matter their capacity. Some journals do offer the cream, for example when some universities reward authors at a considerably higher level for a publication in a high-impact Web of Science indexed journal. But one of the main problems is that overproduction coincides with a dramatic fall in quality (Muller S 2017, written communication, September 4). And, as Phillip de Jager critically observes of the metaphor, '...milk is milk is milk - it is an obvious commodity. Research on the other hand does not need to be a commodity; it can be very valuable and insightful' (de Jager P 2017, written communication, October 15).

There will always be wastage in the system (such as work in progress, incomplete articles, work under revision, unplaced papers), that is, the work that would be more usefully produced as magazine articles or short commentaries. So the debt is sold on down the value chain - to the journals - which do not benefit from incentives, sales or wastage.

The journals - whether funded or not - are, in fact, massively subsidising both the authors and their employers as the publishing costs are rarely recovered by the individual, independent, journals.

\section{What about the workers?}

The issue of payment of editors and reviewers is more vexed. Most humanities and social science publications are produced on a shoestring budget by usually unpaid volunteers (editors, peer reviewers, copy 
editors and assistants) while most authors are in paid employment doing directly rewarded work, using their employers' time and infrastructure to conduct research and write their articles. But editors of self-funded journals often undertake the copy editing, layout and design, marketing etc. on their own. A notable exception is Unisa Press - the only university-based journal publisher in South Africa, which publishes 45 journals, of which 8 are not accredited. Some Unisa Press journals that are indexed by Web of Science, Scopus and IBSS are published in cooperation with Taylor \& Francis, a commercial publisher, whose total South African portfolio is 72 journals. Unisa Press owns 23 and copublishes 22 titles. AOSIS - a local, commercial open-access publisher - publishes 37 titles. The National Inquiry Services Centre (NISC) that cooperates with Unisa Press and Taylor \& Francis, publishes 30 journals, mainly on behalf of scholarly societies in South Africa. The total number of registered South African journals in all disciplines is about 318 .

My analysis now shifts to a single case study of the value chain as an exemplar of how individual journals are subsidising the national research economy. Taking, for example, the 2014 volume of Critical Arts: 30 South African based authors published in six numbers earned for their respective institutions ZAR3.6 million. But not a single cent was directly funnelled by either DHET or the universities represented to the journal which enabled the authors' institutions to cash in to this extent. A managing editor was appointed on a 5-year contract when I as the Journal's Editor-in-Chief moved from the University of KwaZulu-Natal to the University of Johannesburg in February 2015. The University of Johannesburg is now subsidising through this post other institutions, but at UKZN, the managing editor position was largely funded through my own DHET subsidies, derived from my own publication of articles in Critical Arts and other accredited journals, complemented by fundraising and, to a small extent, page charges. Thus, I personally as the Editor-inChief was facilitating huge cash flows to the South African universities to which the Journal's authors were affiliated.

Critical Arts was from 2005 licensed to Unisa Press for the print and Africa market, and to Taylor \& Francis for the electronic platform and global rights. Thus, the goose that lays the golden egg, the journal (and its publishers), is accorded a notional value only by DHET. Although some journals levy page (and other) charges, the administrative cost of recovering them is very high and rarely successful. Pieter Rall, Journals Managing Editor at Unisa Press, suggests that APCs are a fair way to recoup some of the expenses incurred. Practically, this would only be an option for universities that benefit from the DHET incentive. Articles for which APCs have been paid could then be open access (perhaps only for South African institutions). Page budgets and subscription rates would have to be adjusted if there was enough uptake (Rall P 2017, written communication, September 5).

Rent-seeking practices include author pressure on editors to leapfrog production schedules. Threats of withdrawal (and actual withdrawal) occur even after the journal has significantly invested in administration and the peer-review process. A DHET representative at the 2017 Future of Publishing conference convened by CREST, ASSAf and other organisations, mentioned instances of abusive telephone calls made to DHET staff regarding articles published in IBSS-indexed journals which were deemed by DHET to be of a predatory nature (based on Beall's List and work done by Mouton and Valentine ${ }^{4}$ ). Such authors are seeking the rewards attached to measurement systems, rather than the incentive of impacting the discipline, while also mistreating the people administering the system.

The unpaid costs of peer review globally were estimated annually at GBP1.9 billion for 2 million published articles in 2012, from the many millions of submissions ${ }^{15}$ to the core international journal population. Reviewers have to be actively recruited and reminded. This voluntary labour associated with peer review is indirectly costed against reviewers' salaries if employed, their pensions if retired, and their savings if underor unemployed. All the while South African researchers are being invited to offer reviews by predatory journals, which is opportunity cost lost to the country. 'A solution would be for university managers to measure where reviewer effort is going in their universities' (de Jager P 2017, written communication, October 15).
Universities' performance management forms do not always credit editing or reviewing, even as part of official community engagement criteria. In a typical performance management contract, the act of reviewing articles disappears as a minuscule item under 'academic citizenship' that typically counts for $5-10 \%$ of one's key performance areas (KPAs). By far the greatest weighting of KPAs at Unisa, as one illustration, is on research, at $30-50 \%$, next to teaching at $30-50 \%$. In the research KPA, the compulsory weighting is $80 \%$ for published articles ('bonus weights' of $10 \%$ are given for a NRF rating and applying for external grants). The research KPA is the single biggest determinant of an Unisa academic's performance score through which annual bonuses are calculated. The implication is clear: according to university managements, somehow the publication of research just 'takes place', with only the end products valorised. The process of getting research published is completely ignored, or regarded as of little value. Reviewing could be added to one's 'worksheet' on the performance contract. But the KPA that really counts - published articles in 'accredited journals' - is a formalised item to which one cannot add or subtract. Thus reviewing and editing is designed out of the value chain (van den Heever G 2016 written communication, August 31). Such labour becomes an 'after-hours' 'leisure' activity, for which reviewing a single article can take anything from 1 hour to 16 hours. The time:expertise earning ratio is 'written off' as 'service', a donation or unrecoverable expense. The taxpayer pays multiply: (1) taxpayers sponsor the work done by academics, whose universities then, (2) pay to access it in publication form, and who also (3) underwrite the DHET publication incentive. (4) The academic employers subsidise the cost of peer review through their salaries and, finally, (5) editors working during their 'leisure time' subsidise all the components constituting the value chain.

\section{Publication criterion in graduate examination}

Another activity that may be seen as 'milking' the DHET publication subsidy, is the requirement of some universities for the conferral of a graduate degree of either: securing acceptance or publication of an article based on the thesis/dissertation in an accredited journal, or proof of submission thereof. A number of legal and ethical issues may arise from this practice:

- Editors, peer reviewers and publishers may be unaware that they are being implicated in concealed but formal examination processes. Thus are they deceived into offering their unpaid labour and expertise to assist an assessment procedure to which they had not consented nor were contracted to undertake.

- A few journals appear to specifically leverage this sector of the cash cow industry, their editors ensuring that they and their own students publish the majority of articles in these in-house but accredited journals.

- $\quad$ Students are overwhelming accredited journals with submissions, often with no guidance on how to write for journal publication. They are thus stretching journals' costs and capacity to process submissions, and are becoming more and more demanding to be included as rent-seekers. Unisa Press's Communicatio has responded by specifically excluding submissions based on these criteria - unless new knowledge is conveyed - in its guide for authors.

- Where a journal might accept a publication, examiners might have failed the thesis, or vice versa. Thus could arise legal implications for the journals and universities involved.

Few universities agree to even minimal page charges should such student articles be accepted (unbeknownst as part of the examination process); they want their cake and they want to eat it, and thus it is the voluntary labour (editors, reviewers, assistants) who pay the price, who subsidise their peers, who cede their intellectual property in their reports to these authors who want someone else to pay for the costs incurred. ASSAf comments: 'It is recommended that the journal states the submission charges, page fees and APCs in a transparent and simple way, without misleading potential authors' (National Scholarly Editors' Forum circular, 2016 August 29). The funds for such charges are incorporated in the DHET budget, but they are not allocated appropriately throughout the 
value chain by those who are managing it. In other words, (1) university policies decline or limit the payment of charges; (2) authors who will benefit from the DHET incentive often refuse to dip into this payment or their own funds to cover the charges themselves; and (3) DHET pays the journals nothing at all.

It is a wonderful cow's life for the authors and their universities - they get to eat from the state-sponsored trough. But for alienated editors and self-funded journals, well, they are the ones supplying the trough and the largely free feed.

\section{ASSAf and auditing of journals}

This section partially draws on a response invited by ASSAf in 2016 from the Academic and Non-Fiction Authors' Association of South Africa (ANFASA), an advocacy organisation for the protection and advancement of authors' rights.

While university administrations often see journals as cash cows, ASSAf takes a much more critically engaged stance. Its 5-yearly audit cycles attempt to make journals, the missing link in the value chain, but not authors or universities, accountable to the public purse. ASSAf's journals evaluation aims to improve the functioning of the accreditation system, as well as to helpfully encourage the quality of scholarly publication. ${ }^{16}$ Regular assessments examine whether or not journals are of 'sufficiently high quality' and meet 'international standards'. The reviewers evaluate (1) scope and focus; (2) editorial and review processes; (3) authorship; (4) enrichment features; (5) financial sustainability; and (6) international positioning. The 'opportunity for corrective action', or suggestions for improvement, is amongst the recommendations offered by ASSAf panels. ${ }^{17}$

However, the task of rectifying the journal subsidy system is extremely difficult as the DHET list has been unevenly evaluated for the $300+$ DHET registered journals, and is driven by a greater focus on operations than editorial philosophy, or even quality. ASSAf's assumptions include:

1. The continuing dominance of journal articles as the primary output for research done at South African universities. DHET did however recognise the importance of books in 2015, and also creative work. ${ }^{14}$ The new provisions are of special interest to film, television, theatre, dance, video, design, art and fiction writers (and 'plant breeders'). Creative outputs qualify for DHET incentive funding under specific conditions. The legislation does not mention radio, cartooning, motion books (but might include animation as 'film'), digital media or journalism. It does not include non-formal creative interventions, like participatory, forum, educational or street theatre - unless these are research-based and supported by scientific companion outputs also. The legislation specifically excludes self-publishing, but does not define this category. But it does refer to the requirement of a 'credible' publisher able to produce evidence that the work underwent a refereeing process' where novels, poetry, novellas and plays are concerned. This development has resulted from many years of discussion in various fora (NRF ratings committees especially), but the legislation uses archaic (and therefore measurable) categories. 'Authors', like the existing legislation, are assumed to be employees of their institutions, which applies for the award that must undergo a specified peer review process. Peer review significantly includes 'the public domain' - as in theatres, museums and galleries.

2. The continuing significance and effectiveness of accreditation, although DHET is increasingly alert to anomalies. ${ }^{6}$

3. The form of the scholarly journal is assumed as somewhat static, although it is constantly evolving, while the South African Journal of Science is offered as the exemplar.

4. Open access is considered by ASSAf ${ }^{16}$ to be an unmitigated good, especially in the context of using the evaluation process to identify journals to be added to the state-supported SciELO (Scientific Electronic Library Online) open-access platform. SciELO South Africa is a free-to-access searchable collection of selected, South African, open-access, scholarly journals; inclusion in the platform is free for journals. The project is inspired by a global movement towards the implementation of open-access journals, pioneered by the SciELO project, based in Brazil. In this case it is the platform that is supported, not the journals hosted on the platform. ${ }^{18}$

5. While financial sustainability is a significant aspect for the viability of academic journals, it bears little relation to quality. If the intention is to improve financial sustainability, then a DHET journals subvention would be of more assistance than a vague assessment of business processes.

6. International positioning appears to be assessed either by a subjective account of a journal's reputation and reach, or by its listing on the qualifying indexes. However, if such international indexing is so highly valued, then there should be no need to even review journals that are already listed on these platforms a criterion now accepted by ASSAf.

While ASSAf is aware of many contradictions affecting the DHET system $^{16,19}$, some points still need to be flagged. Firstly, a confusion of content with form is evident in the ASSAf questionnaire that asks about hard copy subscription numbers, rather than about subscription bundles. Secondly, some journals that were lauded in some reports have been shown by other ASSAf-commissioned studies presented by CREST at ASSAf-organised National Scholarly Editors' Forum meetings to be overly reliant on authorship from a single institution, in some cases, single individuals seemingly operating as incentive-seeking cash cows. Thirdly, editors are simply assumed to be postmasters shuffling submissions around, when in fact they might be themselves actively shaping a discipline. As one editor of an international journal put it:

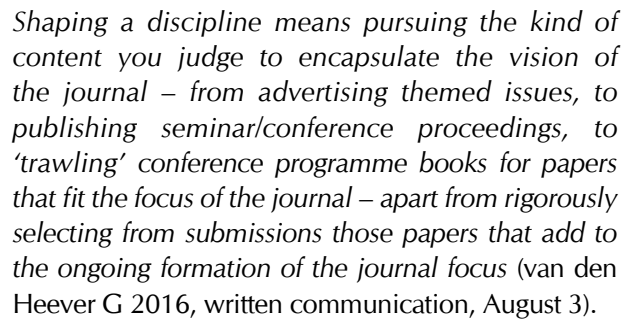
the journal - from advertising themed issues, to publishing seminar/conference proceedings, to 'trawling' conference programme books for papers that fit the focus of the journal - apart from rigorously selecting from submissions those papers that add to the ongoing formation of the journal focus (van den Heever G 2016, written communication, August 3).

The related assumption that competitiveness (in editor and board composition) is better than long-term stability offered by the longerserving editors and boards is another indication that journals are considered merely as supermarkets from which browsers can choose the products that best suit their own needs. In the humanities, single journals can shape entire disciplines:

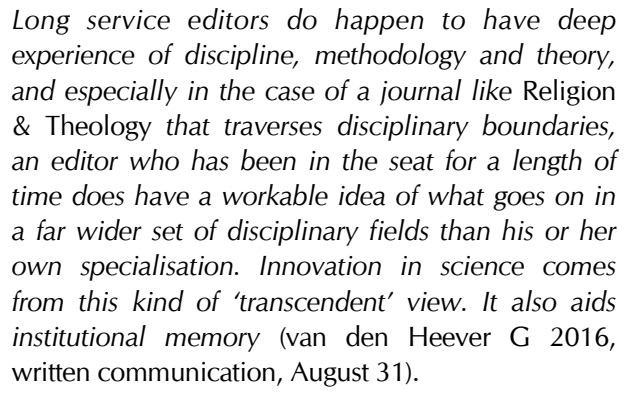

The implicit common assumption that all journals are sustainably funded, with fully resourced secretariats, is to be cautioned. Again, van den Heever paints his own - quite common - humanities experience with Brill, a prominent academic publisher based in Belgium:

\footnotetext{
In some cases disciplinary societies pay for editorial help. I have none. I am the proverbial chef, cook, and bottle washer. I handle the Editorial Manager submission platform, I attend to all copy editing, I do proof reading, I sometimes write reviews, review articles, and some headline articles when I deem it necessary to give the lead in the kind of research and articles the journal should publish. All this without much recognition by the university.
} 
Yet, without journal editors there [would] not be any published research and no research output subsidies. In our case it is as if the university is of the opinion that somehow publications are 'just there'.

In contrast, when Journal for the American Academy of Religion advertised the position of editor, the advert explicitly stated that, along with all the necessary documentation relating to the applicants' own academic profiles, applicants also had to submit an undertaking from their universities regarding (1) a teaching release; (2) provision of an editorial office; and (3) provision of an editorial assistant. 'This is what it means to take editing journals seriously and doing it professionally', concludes van den Heever (2016 August 31). In terms of rent-seeking, thus one institution effectively subsidises all those who publish in the journal - and often the publisher also.

\section{Conclusion: What is the big deal?}

Unless the journals themselves as the most crucial link in the research value chain - and not just universities - are to be funded, sections of the edifice will remain precarious and continued rent-seeking will characterise university research economies, performance management criteria and higher degree administration. The cash cow - the journal - is overburdened, under-fed and producing often sub-standard milk in the absence of sufficient feed.

Structural solutions are required. These solutions include addressing opportunistic institutional rent-seeking morality that has perversely distorted the DHET publication incentive. Overproduction for the sake of the DHET subsidy and key performance indicators should be discouraged. It is also important to recognise that 'some journals only come into existence because of overproduction' (Muller S 2017, written communication, September 4). The subsidy is for universities, not individuals. While individuals within universities will benefit, it cannot be ethically allocated as even taxable take-home pay (Di Parker, Deputy Director-General DHET, CREST conference, 2017 September 27).

The value chain must be assessed and funded in its entirety. Journals are the key link - without journals there are no authors. That is, if the now intensively institutionally embedded DHET system is to continue, credible journals must be directly subsidised and rigorously evaluated by ASSAf on the basis of clear and appropriate replicable methodology across journals. If journal support is implemented then the mechanism must be wary of supporting journals that have only been brought into existence by incentive-seeking. This kind of behaviour can be easily moderated more broadly by capping the number of awards made annually to perhaps 10 articles per author.

ASSAf needs not only to assess individual journals by disciplines, but also entire disciplines in terms of what the 'market' will bear, taking into consideration that markets and quality are not necessarily coincident. The case highlighted by Thomas and De Bruin ${ }^{13}$ of the oversupply of management journals and the consequent overproduction of articles evidencing significant plagiarism is a clear case in point. Similarly, does South Africa really need 24 law journals and 25 theology titles, which individually exceed the actual number of universities? Assessment might include in exceptional cases a sampling of peer review reports and editorial correspondence. Many journals just use tick boxes which discourage substantive engagement with submissions and authors, while many do evidence detailed critique over one or more drafts. This approach would not in the normal course of affairs necessarily constitute editorial interference by ASSAf panels, as it is after all tasked to assess public accountability.

Current debate should hopefully lead to a sustained discussion of the system that includes both editors and publishers.

\section{Acknowledgements}

Thanks to Sean Muller, Johann Mouton, Arnold de Beer, Gerhardus van den Heever, Pieter Rall, Phillip de Jager and Beth le Roux for their comments on different drafts of this article. I thank John Butler-Adam for his extensive critique of my use of the concept of rent-seeking. I also thank ANFASA for providing a venue in which these discussions have been previously flagged (see Le Roux ${ }^{20}$ ). Finally, David Nothling composed the graphic. An overview of the 2017 Future of Publishing conference and slides can be accessed here: http://www0.sun.ac.za/ scicom/?news = dynamics-scholarly-publishing-global-trends-localresponses

\section{References}

1. Larivière $V$, Haustein $S$, Mongeon $P$. The oligopoly of academic publishers in the digital era. PLOS ONE. 2015;10(6), e0127502, 15 pages. https://doi. org/10.1371/journal.pone.0127502

2. Van Noorden R. Open access: The true cost of science publishing. Nature 2013;495:426-429. Available from: https://www.nature.com/news/openaccess-the-true-cost-of-science-publishing-1.12676\#auth-1

3. De Jager P, Van der Spuy P, De Kock F. Do not feed the predators. S Afr J Bus Manage. 2016;48(3):35-45. https://doi.org/10.2139/ssrn.2858750

4. Mouton J, Valentine A. The extent of South African authored articles in predatory journals. S Afr J Sci. 2017;113(7/8), Art. \#2017-0010, 9 pages. https://doi.org/10.17159/sajs.2017/20170010

5. Kerr A, De Jager P. A description of predatory publishing in South African economics departments [document on the Internet]. c2017 [cited 2018 Feb 02]. Available from: https://2017.essa.org.za/fullpaper/essa_3649.pdf

6. Mouton J. Scholarly publishing in SA: The qualitative imperative. c2017 [cited 2018 Feb 02]. Available from: http://www0.sun.ac.za/scicom/wp-content/ uploads/2012/10/Mouton-Scholarly-publishing-in-SA-The-qualitativeimperative.pdf

7. Muller SM. Academics as rent seekers: Distorted incentives in higher education, with reference to the South African case. Int J Educ Develop. 2017;52:58-67. https://doi.org/10.1016/j.ijedudev.2016.11.004

8. Tullock $\mathrm{G}$. The welfare costs of tariffs, monopolies, and theft. Econ Inq. 1986;5(3):224-232. https://doi.org/10.1111/j.1465-7295.1967.tb01923.x

9. Krueger A0. The political economy of the rent-seeking society. Am Econ Rev. 1974;64(3):291-303.

10. Tomaselli KG, Steadman I, Gardner S, Muller J, Tomaselli RE, Bertelsen E, et al. Retrospective. Crit Arts. 1982;2:1.

11. Byrne D. Research in a funding jungle: The South African research accreditation system. Scrutiny2. 1996;1(1/2):1-18.

12. Haivan M. Crises of imagination, crises of power. Capitalism, creativity and the commons. London: Zed Books; 2014.

13. Thomas A, De Bruin GP. Plagiarism in South African management journals. S Afr J Sci. 2015;111(1/2), Art. \#2014-0017, 3 pages. https://doi. org/10.17159/sajs.2015/20140017

14. Government Gazette 597, 2015 March 11, 38552, Clause 5.0(c)

15. Longva L, Reierth $E$, Moksness L, Smedsrød B. Peer reviewing: A private affair between the individual researcher and the publishing houses, or a responsibility of the university? J Electron Publish. 2017;20(1). https://doi. org/10.3998/3336451.0020.103

16. Gevers W, Hammes M, Mati X, Mouton J, Page-Shipp R, Pouris A, editors. Report on a strategic approach to research publishing in South Africa. Pretoria: Academy of Science of South Africa; 2006. https://doi.org/10.17159/ assaf/0038

17. ASSAf. Peer review panels [webpage on the Internet]. No date [cited 2018 Feb 02]. Available from: http://www.assaf.org.za/index.php/programmes/ scholarly-publishing-programme/peer-review-panels

18. ASSAf. SciELO South Africa. No date [cited 2018 Feb 02]. Available from http://www.assaf.org.za/index.php/programmes/scholarly-publishingprogramme/open-access-scielo-south-africa

19. Vaughan CL. Alternatives to the publication subsidy for research funding. S Afr J Sci. 2008;104(3/4):91-96.

20. Le Roux E. Discrimination in publishing. Crit Arts. 2016;29(6):703-704. 